\title{
ANALISIS POLA ARUS AKIBAT PASANG SURUT DI PANTAI SELAT BARU, KABUPATEN BENGKALIS
}

\author{
Swary Aristi $^{1}$, Sigit Sutikno ${ }^{2}$, Manyuk Fauzi ${ }^{3}$ \\ $1,2,3$ Jurusan Teknik Sipil, Fakultas Teknik, Universitas Riau \\ Email: swaryaristi.sa@gmail.com (korespondensi)
}

\begin{abstract}
Bengkalis Island is an archipelago located in Bengkalis Regency, Riau Province. Because it is directly facing the open ocean, causing abrasion to occur on the northern coast of Bengkalis Island. The purpose of this study was to determine the condition of the tidal current pattern in Selat Baru Beach, Bengkalis Regency using a numerical model (hydrodynamics) in the MIKE21 application. The results showed the current velocity of the new strait coast, Bengkalis Regency, Riau Province. Based on the results of the model, it is obtained that the highest tide current that occurs in the western season in 2020 ranges from $0.006 \mathrm{~m} / \mathrm{s}$ to $0.09 \mathrm{~m} / \mathrm{s}$, while the lowest tide current that occurs in the western season ranges from 0.006 to $0.084 \mathrm{~m} / \mathrm{s}$.
\end{abstract}

Keywords: Breakwater, Velocity, Flow Patterns, Hydrodynamics.

\begin{abstract}
Abstrak
Pulau Bengkalis merupakan salah satu wilayah kepulauan yang terdapat di Kabupaten Bengkalis Propinsi Riau. Karena berhadapan langsung dengan lautan yang terbuka, menyebabkan abrasi terjadi di Pantai bagian utara di Pulau Bengkalis. Tujuan dari penelitian ini adalah untuk mengetahui kondisi pola arus akibat pasang surut di Pantai Selat Baru, Kabupaten Bengkalis dengan menggunakan model numerik (hidrodinamika) pada aplikasi MIKE21. Hasil penelitian menunjukkan kecepatan arus pantai selat baru, Kabupaten Bengkalis, Propinsi Riau. Berdasarkan hasil model yang diperoleh bahwa kecepatan arus saat pasang tertinggi yang terjadi pada musim barat pada tahun 2020 berkisar $0.006 \mathrm{~m} / \mathrm{s}$ sampai 0.09 $\mathrm{m} / \mathrm{s}$, sedangkan kecepatan arus saat surut terendah yang terjadi pada musim barat berkisar 0.006 sampai $0.084 \mathrm{~m} / \mathrm{s}$
\end{abstract}

Kata kunci: Breakwater, Kecepatan, Pola Arus, Hidrodinamika

\section{PENDAHuluan}

\subsection{Latar Belakang}

Kabupaten Bengkalis merupakan salah satu Kabupaten di Propinsi Riau yang wilayahnya mencakup daratan bagian timur pulau Sumatera dan wilayah kepulauan, dengan luas 11.481,77 Km2 (Sutikno, 2014). Pantai utara di Pulau Bengkalis merupakan pantai yang mengalami abrasi paling parah, gelombang yang memecah di pantai merupakan penyebab utama abrasi tersebut. Energi gelombang yang cukup besar mampu mengangkut sedimen yang cukup besar dan dalam jumlah yang cukup banyak. Selain itu, arus juga merupakan salah satu faktor penting yang menyebabkan terjadinya pergerakan sedimen yang dapat mengakibatkan abrasi dan sedimentasi. Menurut Sverdrup et al. (1961) arus adalah gerakan air yang mengakibatkan perpindahan horizontal dan vertikal massa air. Dikarenakan keterbatasan peralatan, waktu dan biaya, maka dalam penelitian ini alternatif yang dipilih untuk mengetahui pola arus adalah dengan menggunakan perangkat lunak MIKE 21. Perangkat lunak MIKE 21 merupakan model hidrodinamika yang menggunakan sistem model numerik secara umum untuk memodelkan simulasi muka air dan aliran di estuari, teluk dan pantai. Dari hal tersebut di atas, penting adanya penelitian mengenai perangkat lunak MIKE 21 untuk Simulasi transport sedimen di Pantai Selat Baru, Kabupaten Bengkalis, Propinsi Riau.

\subsection{Tujuan Penelitian}

Tujuan dari penelitian ini adalah untuk mengetahui kondisi pola arus akibat pasang surut di Pantai Selat Baru, Kabupaten Bengkalis dengan menggunakan model numerik (hidrodinamika) pada aplikasi MIKE21. 


\subsection{Batasan Masalah}

Batasan masalah dalam peneilitian ini adalah :

1. Lokasi pantai yang dianalisis adalah Pantai Selat Baru, Kabupaten Bengkalis, Propinsi Riau

2. Data-data yang digunakan sebagai input merupakan data sekunder.

3. Simulasi dan pemodelan dilakukan pada bulan Februari tahun 2020.

4. Permodelan pola dan nilai arus, dilakukan dengan menggunakan aplikasi MIKE 21

\section{Tinjauan Pustaka}

\subsection{Definisi Pantai}

Pantai merupakan batas antara wilayah daratan dengan wilayah lautan. Daerah daratan merupakan daerah yang terletak di atas dan di bawah permukaan daratan dimulai dari batas garis pasang tertinggi. Sedangkan daerah lautan merupakan daerah yang terletak di atas dan di bawah permukaan laut dimulai dari sisi laut pada garis surut terendah, termasuk dasar laut dan bagian bumi di bawahnya.

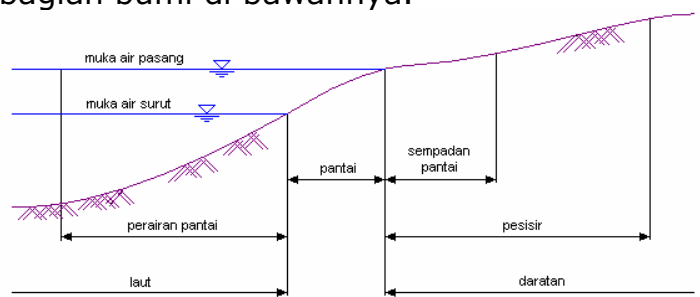

Gambar 1 Definisi dan batasan pantai

Sumber: (Bambang Triadmodjo, 2012)

Menurut Bambang Triadmodjo (2012) yang dijelaskan dalam gambar 1, daerah pantai atau pesisir adalah suatu daratan beserta perairannya dimana pada daerah tersebut masih dipengaruhi baik oleh aktifitas darat maupun aktifitas laut. Pantai adalah daerah di tepi perairan sebatas antara surut terendah dan pasang tertinggi. Garis pantai adalah garis batas pertemuan antara daratan dan lautan. Daratan pantai adalah daerah di tepi laut yang masih dipengaruhi oleh aktifitas laut. Perairan pantai adalah perairan yang masih dipengaruhi oleh aktifitas daratan. Sempadan pantai adalah daerah sepanjang pantai yang diperuntukkan bagi pengamanan dan pelestarian pantai.

\subsection{Pasang Surut}

Pasang surut laut merupakan fenomena naik turunnya muka laut secara periodik yang terjadi di seluruh belahan bumi akibat adanya gaya pembangkit pasang surut yang utamanya berasal dari matahari dan bulan (Douglas, 2001).

Pasang surut muka air laut dapat dianalisis dengan menggunakan metode Least Square. Metode Least Square digunakan untuk menganalisis amplitudo dan fase setiap komponen harmonik pasang surut dari data pasang surut yang diolah. Menurut Ilahude, 1999 dalam Siswanto, 2007 klasifikasi tipe pasang surut didasarkan pada perbandingan antara jumlah amplitude konstanta-konstanta diurnal (K1 dan O1) dengan jumlah amplitude konstantakonstanta semidiurnal (M2 dan S2). Bilangan Formzahl digunakan untuk mengetahui tipe pasang surut yang terjadi diperairan (Mahatmawati, 2009) yang dirumuskan :

$$
\mathrm{F}=\frac{(\mathrm{AK} 1+\mathrm{AO} 1)}{(\mathrm{AM} 2+\mathrm{AS} 2)}
$$

dengan :

$$
\begin{aligned}
\mathrm{F}= & \text { formzahl } \\
\mathrm{AK} 1= & \text { amplitudo dari anak gelombang pasang } \\
& \text { surut harian tunggal rata-rata yang } \\
& \text { dipengaruhi oleh deklinasi bulan dan } \\
& \text { matahari }
\end{aligned}
$$

Menurut Oktavia, 2011 mengatakan bahwa jika nilai $\mathrm{F}$ berada antara :

$0<\mathrm{F} 0,25$ : semidiurnal

$0,25<\mathrm{F}<1,50$ : mixed tideprevailing semi-diurnal

$1,50<F \quad 3,00$ : mixed tide prevailing diurnal

$\mathrm{F}>3,0 \quad$ : diurnal

\subsection{Gelombang}

Gelombang di laut bisa dibangkitkan oleh angin (gelombang angin), gaya tarik matahari dan bulan (pasang surut), letusan gunung berapi atau gempa di laut (tsunami), dan lain sebagainya. Gelombang dapat menimbulkan energi untuk membentuk pantai, menimbulkan arus dan transport sedimen dalam arah tegak lurus dan sepanjang pantai, serta menyebabkan gayagaya yang bekerja pada bangunan pantai. Pasang surut juga merupakan faktor penting karena bisa menimbulkan arus yang cukup kuat terutama di daerah yang sempit, misalnya di teluk, estuari, dan muara sungai. 
Selain itu elevasi muka air pasang dan air surut juga penting untuk merencanakan bangunan-bangunan pantai.

\subsection{Batimetri}

Peta batimetri diperlukan untuk mengetahui kedalaman laut (elevasi) di sekitar lokasi pekerjaan/ penelitian yang dapat digunakan pada kegiatan pengerukan yang dilakukan untuk menentukan volume pekerjaan dan akhirnya menentukan biaya (Nugraha dan Subiyanto, 2014).

\subsection{Gambaran Umum MIKE 21}

Modul hidrodinamik dalam MIKE 21 HD merupakan sistem model numerik secara umum untuk memodelkan simulasi muka air dan aliran di estuari, teluk dan pantai. Model ini dapat mensimulasikan aliran dua dimensi tidak langgeng di dalam fluida satu lapisan (secara vertikal homogen) maupun dalam aliran tiga dimensi. Modul hidrodinamika MIKE 21 merupakan modul dasar dalam program MIKE 21 model aliran (flow model).

\section{Metodologi Penelitian}

\subsection{Lokasi Penelitian}

Lokasi studi penelitian dilakukan pada salah satu pantai di Pulau Bengkalis, yakni Pantai Selat Baru, Kabupaten Bengkalis, Propinsi Riau. Pada lokasi studi penelitian. Koordinat lokasi penelitian pada garis pantai yaitu: Longitude: $102^{\circ} 16^{\prime} 1.84^{\prime \prime} \mathrm{E}$, dan Latitude: $1^{\circ} 33^{\prime} 31.75^{\prime \prime} \mathrm{N}$ sampai Longitude: $102^{\circ} 14^{\prime} 34.01^{\prime \prime E}$, dan Latitude: $1^{\circ} 33^{\prime} 46.98 " N$, dengan luasan area (boundary) yaitu 7,88 $\mathrm{km}$.

\subsection{Perangkat Lunak yang Digunakan}

Pemodelan simulasi menggunakan Modul hidrodinamik dalam MIKE 21. Modul ini merupakan sistem model numerik secara umum untuk memodelkan simulasi muka air dan aliran di estuari, teluk dan pantai. Modul hidrodinamika MIKE 21 (MIKE 21 HD) merupakan modul dasar dalam program MIKE 21 model aliran (flow model).

\subsection{Prosedur Penelitian}

\subsubsection{Pengumpulan Data}

Metode pengumpulan data dalam penelitian ini adalah data sekunder yakni data yang didapat dari data pengukuran penelitian terdahulu serta menggunakan data satelit sebagai pendukung variabel pembangkit model dalam MIKE 21. Adapun data sekunder yang digunakan dalam penelitan ini adalah data pasang surut, data batimetri, dan data historis angin.

\subsubsection{Analisa Komponen Pasang Surut (Least-Square)}

Komponen pasut dapat dianalisa dengan metode harmonik, dengan dasar bahwa pasang surut yang terjadi adalah superposisi atau penjumlahan dari berbagai komponen pasut. Karena sifat pasang surut yang periodik, maka ia dapat diramalkan. Untuk meramalkan pasang surut, diperlukan data amplitudo dan beda fase dari masing-masing komponen pembangkit pasang surut.

Komponen-komponen utama pasang surut terdiri dari komponen tengah harian dan harian. Namun demikian, karena interaksinya dengan bentuk (morfologi) pantai dan superposisi antar gelombang pasang surut komponen utama, akan terbentuklah komponen-komponen pasang surut yang baru.

Data pasang surut diperoleh dari data lapangan bnulan Februari 2016 lalu kemudian dilakukan penggabungan data pasang surut BIG pada bulan Februari 2020, dengan memakai nilai Mean Sea Level (MSL) pada pengolahan data pasang surut. Dengan mengetahui amplitudo komponen tersebut, maka dapat dihitung nilai bilangan Formzalnya dan kemudian tipe pasutnya dapat ditentukan.

Analisis harmonik komponen pasang surut dilakukan untuk mendapatkan nilai amplitudo dan fase dari komponen (M2, S2, $\mathrm{N} 2, \mathrm{~K} 1, \mathrm{O} 1, \mathrm{M} 4, \mathrm{MS} 4$ ) dari data pasang surut.

\subsubsection{Model Hidrodinamika MIKE 21}

Pemodelan numerik dilakukan dengan cara membuat domain model lokasi penelitian. Model ini menggunakan aplikasi aplikasi MIKE 21 Flow Model. aplikasi ini digunakan untuk membuat membuat model hidrodinamik suatu wilayah yang selanjutnya dilakukan verifikasi model.

\subsubsection{Model Arus Pasang Surut}

Simulasi dinamika arus menggunakan model hidrodinamika dengan gaya pembangkit (generating force) pasang surut. Pemodelan arus laut ini dilakukan dengan menggunakan aplikasi MIKE 21 Flow Model. Model MIKE 21 Flow Model adalah model hidrodinamika mengunakan flexible mesh. Dimana model ini dikembangkan untuk aplikasi dalam lingkup oseanografi, pesisir, dan muara. Sistim permodelan ini berdasarkan solusi numerik dari persamaan dua dimensi shallow water equations - 
kedalaman merupakan intergrasi incompressible renolds yang dirata-ratakan dengan persamaan navier stokes.

Persamaan Pembangun

model hidrodinamika ini terdiri dari persamaan kontinuitas dan persamaan gerak dalam arah $x$ dan $y$.

$$
\text { an kontinuitas }
$$$$
\frac{\partial \zeta}{\partial t}+\frac{\partial u}{\partial x}+\frac{\partial v}{\partial y}=0
$$

Persamaan gerak dalam arah $\mathrm{x}$ dan $\mathrm{y}$

$\frac{\partial u}{\partial t}+\frac{\partial}{\partial x}\left(\frac{u^{2}}{h}\right)+\frac{\partial}{\partial y}\left(\frac{u v}{h}\right)+g h \frac{\partial \zeta}{\partial x}+$

$\frac{g u \sqrt{u^{2}+v^{2}}}{c^{2} \cdot h^{2}}=0$

$$
\begin{aligned}
& \frac{\partial v}{\partial t}+\frac{\partial}{\partial y}\left(\frac{v^{2}}{h}\right)+\frac{\partial}{\partial x}\left(\frac{u v}{h}\right)+g h \frac{\partial \zeta}{\partial y}+ \\
& \frac{g v \sqrt{u^{2}+v^{2}}}{c^{2} \cdot h^{2}}=0
\end{aligned}
$$

dimana :

$h(\mathrm{x}, \mathrm{y}, \mathrm{t})=$ kedalaman $\operatorname{air}(\mathrm{m})$

$\partial(x, y, t)=$ variabel yang bervariasi terhadap waktu dan ruang

$\zeta(x, y, t)=$ elevasi permukaan $(\mathrm{m})$

$u, v(\mathrm{x}, \mathrm{y}, \mathrm{t})=$ kecepatan dalam arah $-\mathrm{x}$ dan $-\mathrm{y}$

$c(\mathrm{x}, \mathrm{y})=$ chezy resistance $(\mathrm{m} 1 / 2 / \mathrm{s})$

$g \quad=$ percepatan gravitasi $(\mathrm{m} / \mathrm{s} 2)$

Untuk penentuan langkah waktu (time step interval) dalam simulasi di tentukan berdasarkan kriteria CFL (Courant-FrederickLewy), yaitu :

$$
\begin{aligned}
\Delta t \leq & \frac{\Delta x}{\sqrt{g \cdot H_{\max }}} \\
\text { dimana } & \text { : } \\
\Delta t & =\text { langkah waktu (time step } \\
& \text { interval) }(\mathrm{s}) \\
\Delta x & =\text { grid spasi }(\mathrm{m}) \\
H_{\max } & =\text { kedalaman maksimum }(\mathrm{m}) \\
g & =\text { percepatan gravitasi }(\mathrm{m} / \mathrm{s} 2)
\end{aligned}
$$

\section{Hasil dan Pembahasan}

\subsection{Pasang Surut Laut}

Hasil pemodelan hidrodinamika dengan data kecepatan arus dan pasang surut hasil pengukuran observasi lapangan Februari 2016 (dimodifikasi dengan data pasang surut BIG Februari 2020). Perbandingan antara pasang surut hasil pemodelan dengan pengukuran nilai Formzhal yang akan menentukan tipe pasang surut yang terjadi di lokasi penelitian.
Terdapat 9 komponen utama pasang surut yang menunjukkan hasil Mean Sea Level (MSL) yaitu 1.61 Meter pada daerah penelitian. Komponen pasang surut ini nantinya akan menghasilkan nilai Formzhal yang akan menentukan tipe pasang surut yang terjadi di lokasi penelitian. Pada hasil ini nantinya akan menjadi dasar dalam membentuk prediksi nilai pasang surut. Nilai Formzhal yang diperoleh adalah 0,304 yakni masuk dalam kategori pasang surut semidiurnal atau biasa disebut dengan campuran condong ke ganda, dengan makna yaitu dalam satu hari akan terjadi dua kali pasang dan dua kali air surut, Periode pasang surut yang terjadi adalah 12 jam 24 menit.

\subsection{Batimetri}

Data batimetri di dalam penelitian ini adalah menjadi dasar yang sangat dibutuhkan untuk melakukan model hidrodinamika dalam transport sedimen di area pantai selat baru, Bengkalis, Riau. Hal ini menunjukkan dengan batimetri nantinya akan membentuk sebuah topografi dasar perairan yang sangat mempengaruhi dalam proses transpor hidrodinamik (Ji 2008).

Untuk membangun peta batimetri (mesh batimetri) di dalam proses pembuatan model transport sedimen di daerah penelitian membutuhkan data pengukuran kedalaman yang memiliki variabel $x, y$, dan $z$. Perolehan data kedalaman dilakukan secara sekunder menggunakan data BATNAS pada tahun 2020 di area penelitian.

Hasil mesh batimetri yang terlihat pada Gambar 2 yaitu menunjukkan batas area (Boundary) dalam pembuatan model hidrodinamika yang dilakukan dalam penelitian ini

\subsection{Pola dan Kecepatan Arus}

Hasil running model arus untuk pasang tertinggi dan surut terendah untuk tanggal 1 sd 29 Februari 2020, menunjukkan hasil yang memiliki perbedaan yang signifikan setiap harinya dengan perlakukan identifikasi nilai dan pola arus saat kondisi pasang tertinggi dan surut terendah. Hasil pemodelan nilai arus saat pasang tertinggi dapat dilihat pada Gambar 1 sedangkan nilai arus pada saat surut terendah dapat dilihat pada Gambar 2. 


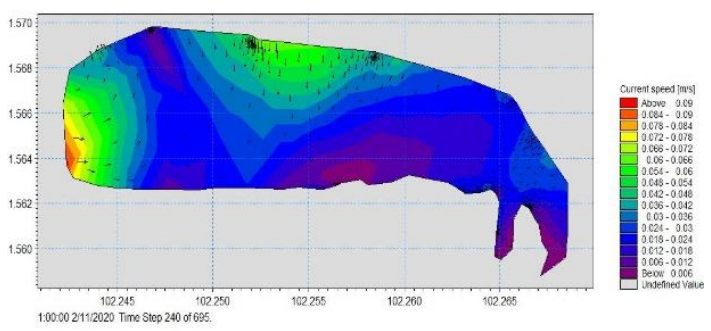

Gambar 1. Pola dan kecepatan arus, nilai kecepatan arus tertinggi pada saat pasang tertinggi (Tanggal 11 Februari 2020, pukul 01.00 WIB)

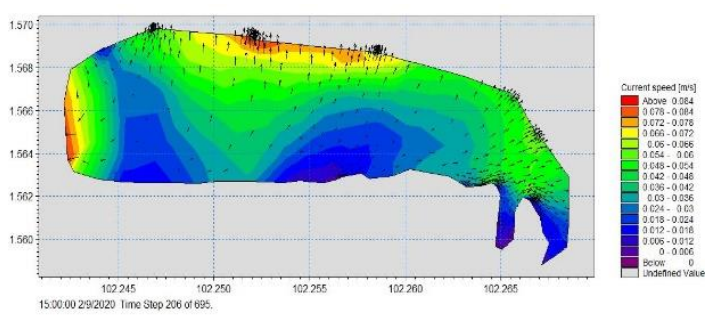

Gambar 2. Pola dan kecepatan arus, nilai kecepatan arus tertinggi pada saat surut terendah (Tanggal 9 Februari 2020, pukul 15.00 WIB)

Berdasarkan hasil model yang diperoleh pada pantai selat baru, Kabupaten Bengkalis, Propinsi Riau, bahwa kecepatan arus saat pasang tertinggi yang terjadi pada musim barat pada tahun 2020 berkisar 0.006 sampai 0.09 m/s (Gambar 1), sedangkan kecepatan arus saat surut terendah yang terjadi pada musim barat berkisar 0.006 sampai 0.084 $\mathrm{m} / \mathrm{s}$ (Gambar 2).

Hasil model kecepatan arus laut pada tahun 2020 bulan februari yang dihasilkan pada saat pasang tertinggi musim barat menunjukkan arah berasal dari utara dan menuju barat laut pada daerah sekitar pantai selat baru, Riau. Hasil pemodelan kecepatan arus laut saat surut terendah musim barat yang berada di utara pantai Selat Baru, Propinsi Riau memiliki arah kecepatan arus laut yang berasal dari barat menuju ke arah utara. Hal ini menunjukkan kecepatan dan pola arus permukaan laut memiliki peran besar terhadap terjadinya transport sedimen (Rachmat \& Purwanto, 2011).

\section{Kesimpulan dan Saran}

\subsection{Kesimpulan}

Berdasarkan hasil analisis data dan pembahasan yang telah dilakukan di atas, maka dapat disimpulkan pola arus akibat pasang surut di Pantai Selat Baru Kabupaten
Bengkalis memiliki peran besar terhadap terjadinya transpor sedimen.

\subsection{Saran}

Saran yang berikan berdasarkan hasil kajian dari penelitian ini, yakni perlu adanya analisis lanjutan terkait transpor sedimen yang terjadi di Pantai Selat Baru, Kabupaten Bengkalis Propinsi Riau guna untuk mengetahui bagaimana pola dan besaran sedimen pada lokasi tersebut.

\section{DAFTAR PUSTAKA}

[1] Douglas, B. C. (2001). Sea level change in the era of the recording tide gauge. In International Geophysics (Vol. 75, pp. 37-64). Academic Press.

[2] Douglas, R. M. (2001). Physical Oceanography. Department of Geophysical Science. University of Chicago, Illinois.

[3] Ji, Z. G. (2017). Hydrodynamics and water quality: modeling rivers, lakes, and estuaries. John Wiley \& Sons.

[4] Mike, D. H. I. (2007). Flow Model Flexible Mesh. DHI Aplikasi.

[5] Nugraha, A. L., \& Subiyanto, S. (2014). Analisis Pengukuran Batimetri Dan Pasang Surut Untuk Menentukan Kedalaman Kolam Pelabuhan (Studi Kasus: Pelabuhan Tanjung Perak, Surabaya). Jurnal Geodesi Undip, 3(4), 25-36.

[6] Oktavia R.2011. Variasi muka laut dan arus geostropik permukaan perairan selat Sunda berdasarkan data pasut dan angin tahun 2008. Bogor: Program Studi Ilmu dan Teknologi Kelautan, IPB.

[7] Rachmat, B., \& Purwanto, C. (2011). Morfologi Dasar Laut Kaitannya Dengan Proses Abrasi Pantai Di Perairan Pulau Marore, Sulawesi Utara. Jurnal Geologi Kelautan, 9(1), 29-44.

[8] Siswanto, A. D. (2007). Karakteristik pasang di perairan Tanjung Emas Semarang. Jurnal Kelautan, 1(1), 14-21.

[9] Sutikno, S. (2014). Analisis Laju Abrasi Pantai Pulau Bengkalis dengan Menggunakan Data Satelit, 616-625.

[10] Sutikno, S. (2014). Analisis Laju Abrasi Pantai Pulau Bengkalis dengan Menggunakan Data Satelit. Pertemuan Ilmiah Tahunan (PIT) HATHI (Himpunan Ahli Teknik Hidraulik Indonesia) XXXI, 22-24.

[11] Sutikno, S. (2014). Rate of Shoreline Change Analysis of Bengkalis Coast Using Satellite Imagery Data. The 31st 
Annual Conference of Indonesian Association of Hydraulic Engineer, 616625.

https://doi.org/10.13140/RG.2.1.2074. 5766

[12] Triatmodjo, B. (2012). Perencanaan Bangunan Pantai. Yogyakarta: Beta Offset

[13] Triatmodjo, B. (2012). Teknik Pantai, Beta offset, Yogyakarta. Bambang Triatmodjo.

[14] Water, D. H. I. (2012). Environment: DHI Eutrophication Model 1. ECO Lab Template, DHI Water \& Environment, Denmark. 